\title{
Coherent Motion Sensitivity and Reading Development in the Transition From Prereading to Reading Stage
}

\author{
Bart Boets and \\ Maaike Vandermosten \\ Katholieke Universiteit Leuven
}

\author{
Piers Cornelissen \\ University of York
}

\author{
Jan Wouters and Pol Ghesquière \\ Katholieke Universiteit Leuven
}

\begin{abstract}
Evidence suggests that sensitivity to coherent motion (CM) is related to reading, but its role in the etiology of developmental dyslexia remains unclear. In this longitudinal study, CM sensitivity was measured in 31 children at family risk for dyslexia and 31 low-risk controls. Children, diagnosed with dyslexia in third grade (mean age $=8$ years 3 months), demonstrated reduced CM sensitivity in kindergarten (mean age $=5$ years 8 months), before they had learned to read. Preschool CM thresholds in controls also uniquely predicted future literacy achievement. When reassessed in first grade, CM sensitivity in the dyslexic children was age appropriate, and CM thresholds in the controls no longer predicted literacy acquisition. These findings contribute to the debate about the developmental relations between visual processing and reading acquisition.
\end{abstract}

Developmental dyslexia (hereafter referred to as dyslexia) is a hereditable condition that is characterized by severe reading and spelling problems that are persistent and resistant to remediation (Vellutino, Fletcher, Snowling, \& Scanlon, 2004). There is a consensus that dyslexia results from problems in processing, accessing, or adequately representing speech sounds, and this is commonly referred to as a phonological deficit (see Snowling, 2000). In addition, there exists a substantial body of research investigating the different ways that individuals with dyslexia process visual information compared to typically developing age-matched controls (for reviews, see Boden \& Giaschi, 2007; Lovegrove, 1996; Nandakumar \& Leat, 2008). At present, the conceptual framework that best captures the most

Bart Boets is a postdoctoral research fellow of the Research Foundation Flanders. Maaike Vandermosten is a junior research fellow of the Research Foundation Flanders.

This research was financed by the fund for Scientific Research Flanders, Grants G0216.02 and G0331.08, and by a grant from the Research Council of Katholieke Universiteit Leuven, OT/07/034. We are grateful to all children, teachers, and schools who participated in this study. Special thanks are due to Rachel Fouladi for advice about statistical modeling.

Correspondence concerning this article should be addressed to Bart Boets, Centre for Parenting, Child Welfare and Disabilities, Katholieke Universiteit Leuven, Vesaliusstraat 2, 3000 Leuven, Belgium. Electronic mail may be sent to bart.boets@ped. kuleuven.be. commonly observed pattern of differences in visual processing is known as the magnocellular deficit theory of dyslexia (Stein, 2001; Stein \& Walsh, 1997).

The subcortical retinogeniculate and geniculocalcarine visual pathways of the macaque and human comprise at least two parallel divisions: the magnocellular or $\mathrm{M}$ stream and the parvocellular or P stream (Merigan \& Maunsell, 1993; Nassi \& Callaway, 2009; see Hendry \& Reid, 2000, for a discussion of an additional koniocellular pathway). Axons from large $\mathrm{M}$ and small $\mathrm{P}$ retinal ganglion cells project, respectively, to the magnocellular and parvocellular layers of the dorsal lateral geniculate nucleus (LGN) of the thalamus. From the LGN, magnocellular and parvocellular neurons project to separate layers in the primary visual cortex, V1, and this anatomical segregation is at least partially maintained in the next visual area, V2. It has been shown that the magnocellular pathway is involved in the processing of temporal change and lowcontrast information and is tuned to low spatial frequencies. By comparison, the parvocellular pathway is involved in the processing of chromatic

(C) 2011 The Authors

Child Development (c) 2011 Society for Research in Child Development, Inc. All rights reserved. 0009-3920/2011/8203-0011

DOI: 10.1111/j.1467-8624.2010.01527.x 
information and is tuned to low temporal and high spatial frequencies (Boden \& Giaschi, 2007). Starting in the primary visual cortex, two additional anatomical streams for processing visual information have been identified (Goodale \& Milner, 1992; Livingstone \& Hubel, 1988; Merigan \& Maunsell, 1993; Mishkin, Ungerleider, \& Macko, 1983). The dorsal stream, also known as the "where" stream, connects V1 to the posterior parietal cortex and has been implicated in object localization, motion perception, visual attention, and goal-directed behavior. The ventral stream, or "what" stream, connects V1 to the inferotemporal region, and has been implicated in object identification. The dorsal stream includes area V5 (also called MT, medial temporal cortex). This area is known to play a key role in motion perception and is specifically activated when observers are presented with random dot kinematograms (RDKs) containing coherent motion (CM). The ventral stream includes area V4, which has been shown to be specialized for processing color and form (Livingstone \& Hubel, 1988; Zeki, 1978). As noted by Skottun and Skoyles (2006, 2008), some authors have sought to extend the concept of the magnocellular system to include the dorsal stream (Stein, 2001, 2003) or to extend the parvocellular system to include the ventral cortical stream (e.g., Edwards et al., 2004). However, this conceptualization is problematic because the dorsal stream, in addition to the predominant magnocellular input, also receives considerable input from the parvocellular and koniocellular systems (e.g., Nassi, Lyon, \& Callaway, 2006), and the ventral stream receives about equally strong inputs of magno- and parvocellular origin (Martin, 1992).

A number of studies have explored the spatiotemporal contrast sensitivity surface of individuals with dyslexia and nondisabled readers. Individuals with dyslexia have repeatedly demonstrated elevated thresholds for stimuli that optimally activate the subcortical magnocellular pathway (for a review, see Lovegrove, 1996; but see Skottun, 2000, for a critical revision). Commensurate results have been obtained with stimuli that target cortical dorsal stream processing, such as the detection of $\mathrm{CM}$ in RDKs (Britten, Shalden, Newsome, \& Movshon, 1992). A systematic review reveals significantly elevated $\mathrm{CM}$ detection thresholds in dyslexia for 20 of 26 studies (Conlon, Sanders, \& Zapart, 2004; Cornelissen, Richardson, Mason, Fowler, \& Stein, 1995; Edwards et al., 2004; Everatt, Bradshaw, \& Hibbard, 1999; Gibson, Hogben, \& Fletcher, 2006; Hansen, Stein, Orde, Winter, \& Talcott, 2001; Kim, Davis, Burnham, \& Luksaneeyanawin, 2004;
Pellicano \& Gibson, 2008; Raymond \& Sorensen, 1998; Ridder, Borsting, \& Banton, 2001; Roach \& Hogben, 2004; Samar \& Parasnis, 2005; Slaghuis \& Ryan, 1999; Solan, Shelley-Tremblay, Hansen, \& Larson, 2007; Sperling, Lu, Manis, \& Seidenberg, 2006; Talcott et al., 1998; Talcott et al., 2003; Talcott, Hansen, Assoku, \& Stein, 2000; Wilmer, Richardson, Chen, \& Stein, 2004; Witton et al., 1998; no significant group differences in Amitay, Ben-Yehudah, Banai, \& Ahissar, 2002; Hutzler, Kronbichler, Jacobs, \& Wimmer, 2006; Kim \& Davis, 2004; Kronbichler, Hutzler, \& Wimmer, 2002; Tsermentseli, O'Brien, \& Spencer, 2008; White et al., 2006). In addition, 4 studies that applied discriminant analysis to classify dyslexic and normal readers on the basis of CM thresholds, reported percentages of correctly classified individuals that ranged from $67 \%$ to $94 \%$ (Conlon et al., 2004; Solan et al., 2007; Talcott et al., 1998; Talcott et al., 2003). Functional imaging studies have also confirmed that activation of area V5/MT in response to CM stimuli is not as robust in adults with dyslexia compared to controls (Eden et al., 1996) and that the magnitude of the BOLD-response (i.e. blood-oxygen-level dependence) in this area in response to coherently moving dots is significantly related to reading skills (Demb, Boynton, \& Heeger, 1997). In psychophysical studies, CM thresholds have been related to various aspects of reading ability, orthographic ability, and letter position encoding (Conlon et al., 2004; Cornelissen, Hansen, Gilchrist, et al., 1998; Cornelissen, Hansen, Hutton, et al., 1998; Hulslander et al., 2004; Kim et al., 2004; Samar \& Parasnis, 2005; Solan et al., 2007; Sperling et al., 2006; Talcott et al., 1998; Talcott et al., 2000; Walker, Hall, Klein, \& Phillips, 2006; Wilmer et al., 2004; Witton et al., 1998). However, the evidence for reduced visual motion sensitivity in dyslexia is not unequivocal because a number of studies have failed to replicate the finding (e.g., Amitay et al., 2002; Hutzler et al., 2006; Kim \& Davis, 2004; Kronbichler et al., 2002; Tsermentseli et al., 2008; White et al., 2006). In addition, the phenomenon of reduced visual motion sensitivity is not exclusive to dyslexia; elevated CM thresholds have also been observed in other developmental disorders, such as autism (e.g., Milne et al., 2002) and Williams syndrome (e.g., Atkinson et al., 1997).

The relation between visual word recognition skills, contextual reading, and the ability to detect $\mathrm{CM}$ in a RDK is not immediately obvious. In a recent review, Boden and Giaschi (2007) identified a number of cognitive and perceptual processes that they argue depend on dorsal stream processing (as 
indexed by $\mathrm{CM}$ sensitivity) and that are critical for fluent reading and efficient visual word recognition. Specifically, they make the case for visual attention (e.g., Vidyasagar, 2004), letter position encoding (e.g., Cornelissen, Hansen, Gilchrist, et al., 1998), binocular stability (e.g., Stein \& Fowler, 1993), and oculomotor control (e.g., Pavlidis, 1981), all of which are likely to play a role in reading development, and have been found to be impaired in individuals with dyslexia and in unselected individuals with poor CM sensitivity (Cornelissen, Hansen, Gilchrist, et al., 1998; Cornelissen, Hansen, Hutton, et al., 1998).

It is tempting to interpret the association between reduced $\mathrm{CM}$ sensitivity and dyslexic status together with the observed correlations between $\mathrm{CM}$ sensitivity and a variety of reading and reading related tasks as evidence that adequate visual motion processing (and by implication dorsal visual stream integrity) is required for reading success (Stein, 2001; Stein \& Talcott, 1999; Stein \& Walsh, 1997). However, cause and effect may be the other way round: low-level visual processing difficulties could result from poor literacy skills and reduced print exposure (Ramus, 2003; Talcott \& Witton, 2002). Alternatively, it is equally possible that reduced CM sensitivity could simply be an epiphenomenal marker for the dyslexic brain. In the light of the emerging view that risk factors in developmental disorders are probabilistic rather than deterministic (e.g., Pennington, 2006), discriminating between these alternatives may constitute a major scientific challenge.

To our knowledge, all previous studies of visual motion sensitivity and dyslexia have measured CM sensitivity at a single point in time, after reading acquisition had begun and in the case of individuals with dyslexia, when reading problems were already apparent. Therefore, it is impossible to disentangle cause from effect in these studies. What is needed are longitudinal data: specifically, measurement of $\mathrm{CM}$ thresholds in prereaders who are then followed up longitudinally to test whether early CM sensitivity predicts later reading skill and the likelihood of a diagnosis of dyslexia. Therefore, in this study, we investigated the development of $\mathrm{CM}$ sensitivity and literacy skills in two groups of children: a group of children at risk of developing dyslexia based on family history and a low-risk control group of the same chronological age. CM thresholds were measured twice, once in kindergarten and a second time in first grade. Measures of literacy achievement were administered in kindergarten, first grade, and third grade. Dyslexia diagnoses were made based on firstand third-grade reading and spelling scores. When the first CM thresholds were obtained in kindergarten, children knew on average fewer than three letters $(M=2.5, S D=3.4$; Boets, Wouters, van Wieringen, \& Ghesquiere, 2006a), thereby justifying their status as prereaders. In a previous record of this study (Boets, Wouters, van Wieringen, \& Ghesquiere, 2006b), we reported a significant concurrent correlation between CM sensitivity and letter knowledge assessed in kindergarten. In this report, we describe the crucial retrospective analysis where we compare CM thresholds assessed in kindergarten and first grade of children who had been diagnosed as dyslexic or nondyslexic on the basis of their first and third grade reading and spelling scores. Concurrent and predictive relations between CM sensitivity and literacy achievement are also investigated.

\section{Method \\ Participants}

\section{General Characteristics}

Sixty-two White children participated in the study (26 girls and 36 boys). They were followed from the last year of kindergarten (mean age $=$ 5 years 6 months), which is 1 year before the onset of formal reading instruction in Belgium, until the start of third grade of primary school (mean age $=8$ years 3 months), by which time they had received 2 years and 2 months of reading instruction. All children were native Dutch speakers with no known history of neurological or psychiatric conditions, hearing loss, or visual problems. None of the children had been prescribed psychoactive medication. On the days when they were tested, no child presented gross deficiencies in visual acuity (Landolt-C single optotypes Snellen acuity > 0.85) and/or pure-tone audiometry (audiometric puretone average $<25 \mathrm{~dB}$ HL) Mean age while collecting CM data was 5 years 8 months in kindergarten and 6 years 8 months in first grade. At each measurement time point in the study, all CM data were collected within a period of 45 days. Children's mean age while collecting literacy measures was 5 years 6 months in kindergarten, 6 years 10 months in first grade, and 8 years 3 months in third grade. At each time point, all literacy measures were collected within a period of 2 weeks.

\section{Group Assignment}

Half of the participants $(n=31)$ were selected because of a family history of dyslexia; that is, they 
had at least one first-degree relative with a formal dyslexia diagnosis. Since the incidence of dyslexia tends to run in families, such children are known to be more likely to develop reading problems (Gilger, Pennington, \& DeFries, 1991). We refer to these children as the high-risk group (HR). The other half of the participants $(n=31)$ came from families where there was no history of reading disability. We refer to these children as the low-risk group (LR). For every HR child we selected the best matching LR control in kindergarten based on five criteria: (a) educational environment, that is, same nursery school; (b) gender; (c) chronological age; (d) nonverbal intelligence; and (e) parental educational level. Nonverbal intelligence was assessed in kindergarten by the Raven's Colored Progressive Matrices Test (Raven, Court, \& Raven, 1984), which measures spatial reasoning. Only children with nonverbal IQ scores above 80 were included into the study. In addition, the vocabulary and block design subtests of the Wechsler Intelligence Scale for Children (WISC-III; Wechsler, 1992) were administered once children reached first grade, but these tests were not used for participant selection or participant matching. Parental educational level was determined with the International Standard Classification of Education scale (Organisation for Economic Co-operation and Development, 1999). To fit the contemporary educational system in Belgium, the original seven categories of this scale were converted to three categories, comprising low, medium, and high educational levels. Further details about the participants and the selection procedure are described in Boets et al. (2006a).

In line with current practice in Belgium and the Netherlands (Gersons-Wolfensberger \& Ruijssenaars, 1997), the criterion we used for the diagnosis of dyslexia took account of both the severity and the persistence of a child's literacy problems. Specifically, a child had to score below the 10th percentile on a standardized word reading (van den Bos, Spelberg, Scheepstra, \& De Vries, 1994) or spelling test (Dudal, 1997), in both first and third grades. For this study, this rendered 5 children with dyslexia in the LR group $(5 / 31=16 \%)$ and 11 in the HR group $(11 / 31=35 \%)$. By combining risk status (HR or LR) with the presence or absence of a diagnosis of dyslexia, we further divided children into four groups: (a) dyslexic readers at high family risk $(n=11),(b)$ dyslexic readers at low family risk $(n=5)$, (c) nondyslexic readers at high family risk $(n=20)$, and (d) nondyslexic readers at low family risk $(n=26)$. Although this classification would in principle render a convenient $2 \times 2$ design for data analysis (albeit with unequal participant numbers per group), it would have little statistical power. Therefore, to improve statistical power, we sought to combine the dyslexic HR and dyslexic LR groups. To justify this, we tested whether the two dyslexic groups differed on any of the tests administered, and they did not (all $p>.20$, with Cohen's $d$ ranging between -0.17 and 0.13 ). Accordingly, the data for both dyslexic groups were collapsed into a single dyslexic sample, thereby rendering three groups for final analyses: (a) dyslexic readers (D: $n=16$ ), (b) nondyslexic readers at high family risk (NHR: $n=20$ ), and (c) nondyslexic readers at low family risk (NLR: $n=26$ ). Table 1 displays descriptive statistics for the three groups. Children in the dyslexic group scored significantly poorer than both other groups on reading and spelling (mixed model analysis [MMA], all $p \mathrm{~s}<.0001$, Tukey corrected, $d$ ranging between -2.72 and -1.51 ). Children in the NHR group also scored significantly lower than children in the NLR group on first- and third-grade spelling (MMA, $p<.05$, Tukey corrected, $d=-0.62$ and -0.76 in first and third grades, respectively). The three groups did not differ in gender ratio, $\chi^{2}(2$, $N=62)=1.29, p=.53$, age, nonverbal intelligence (Raven's Progressive Color Matrices), vocabulary (WISC-III), block design (WISC-III), or parental educational level (MMA, all $p s>.10$, ds ranged between -0.49 and 0.12). This outcome, though favorable to the final analyses, was not designed and was not expected, a priori, because the individual matching in kindergarten was originally accomplished at the level of the family risk status without considering actual reading status, and because the Vocabulary and Block Design subtests of WISC-III were not used in the matching of the participant samples.

\section{Comorbid Attention Problems}

Although none of the participants was diagnosed with attention deficit hyperactivity disorder (ADHD) or attention deficit disorder (ADD), we additionally wanted to control for the typically increased incidence of attention-related disorders in individuals with dyslexia (e.g., Willcutt \& Pennington, 2000). Therefore, the teacher completed an ADHD rating scale for every child at the end of first grade (Scholte \& van der Ploeg, 1998). This psychometrically valid and reliable questionnaire contains 18 items that are directly related to Diagnostic and Statistical Manual of Mental Disorders, fourth edition (DSM-IV) diagnostic criteria for ADHD. It assesses the presence of inattentive, 
Table 1

Characteristics of the Participant Groups

\begin{tabular}{|c|c|c|c|c|c|c|}
\hline \multirow[b]{2}{*}{ Characteristics } & \multicolumn{2}{|c|}{$\begin{array}{l}\text { Dyslexic group } \\
\quad(n=16)\end{array}$} & \multicolumn{2}{|c|}{$\begin{array}{l}\text { Nondyslexic } \\
\text { high-risk group } \\
(n=20)\end{array}$} & \multicolumn{2}{|c|}{$\begin{array}{l}\text { Nondyslexic } \\
\text { low-risk group } \\
(n=26)\end{array}$} \\
\hline & $M$ & $S D$ & $M$ & $S D$ & $M$ & $S D$ \\
\hline \multicolumn{7}{|l|}{ Subject characteristics } \\
\hline Sex (male:female) & 11:5 & & $10: 10$ & & $15: 11$ & \\
\hline Age in months (kindergarten) & 68 & 3 & 68 & 3 & 68 & 3 \\
\hline Nonverbal IQ (Raven in kindergarten) ${ }^{\mathrm{a}}$ & 105 & 9 & 107 & 17 & 112 & 14 \\
\hline Vocabulary (WISC-III in Grade 1$)^{\mathrm{b}}$ & 10 & 2 & 10 & 3 & 11 & 2 \\
\hline Block design (WISC-III in Grade 1$)^{\mathrm{b}}$ & 10 & 3 & 11 & 2 & 10 & 3 \\
\hline Maternal educational level & 2.5 & 0.7 & 2.6 & 0.6 & 2.6 & 0.6 \\
\hline Paternal educational level & 2.4 & 0.6 & 2.1 & 0.8 & 2.3 & 0.6 \\
\hline \multicolumn{7}{|l|}{ Defining literacy measures } \\
\hline Word reading (Grade 1$)^{\mathrm{a}}$ & 80 & 8 & 100 & 8 & 104 & 10 \\
\hline Spelling (Grade 1) ${ }^{\mathrm{a}}$ & 76 & 14 & 94 & 11 & 101 & 12 \\
\hline Word reading (Grade 3$)^{a}$ & 69 & 18 & 96 & 10 & 102 & 13 \\
\hline Spelling (Grade 3) ${ }^{\mathrm{a}}$ & 74 & 8 & 92 & 10 & 100 & 11 \\
\hline
\end{tabular}

Note. Parental educational level was calculated from ordinal data. The correspondence in frequency distribution was also confirmed using Fisher's exact test. WISC-III = Wechsler Intelligence Scale for Children.

a Standardized scores with population average: $M=100$ and $S D=15$.

${ }^{\mathrm{b}}$ Standardized scores with population average: $M=10$ and $S D=3$.

hyperactive and impulsive behavior on a 5-point scale, as perceived during the last 6 months. Group comparisons confirmed that children in the dyslexic group obtained significantly higher scores than children in the NHR and NLR groups on the inattentive subscale (MMA, $p<.05$, Tukey corrected, $d s=0.71$ and 1.13 , respectively), but not on the hyperactive or impulsive subscales, or on the combined summarizing scale (MMA, $p>.10$, ds ranged between 0.19 and 0.49). At an individual level, 4 children with dyslexia, 1 NHR child, and 2 NLR children scored in the clinical range, which may be suggestive for ADHD-related problem behavior. As we wished to retain a representative sample, no participants were excluded from the analyses, but individual differences in attention were statistically controlled for in an additional series of analyses.

\section{Measures}

\section{Literacy Measures}

Kindergarten letter knowledge. To obtain a preliminary measure of prereading skills, the 16 most frequently used letters in Dutch books were presented on a card and the child had to name each of these letters. Accurately reporting either the sound or the name of a letter was considered a correct response. The maximum score on the test was 16.

Grade 1 letter knowledge. The test measured the accuracy for naming the sound of Dutch letters and letter combinations. Forty-two graphemes and grapheme combinations were presented on a card and the child had to read them as accurately as possible. The maximum score on the test was 42 .

Word reading. The One-Minute Reading test (van den Bos et al., 1994) was used as a standardized measure of single word identification. This test combines speed and accuracy into one index score. The child had to read a list of words of increasing difficulty as correctly and quickly as possible. The score on the test is the number of words read correctly within $1 \mathrm{~min}$. For diagnostic purposes, this score was transformed to an age-adjusted standard score relative to population average.

Nonword reading. The Pseudo-Word Reading test (van den Bos et al., 1994) offers a combined measure of speed and accuracy of nonword reading. The child had to read a list of nonwords of increasing difficulty as correctly and quickly as possible. The score on the test is the number of nonwords read correctly within 2 min.

Word reading accuracy. The construction of this test was similar to the one described by de Jong and Wolters (2002). The test consisted of 40 items that were gradually increasing in difficulty level. 
This was accomplished by increasing the word length and by using less frequent letters, letter clusters, and words. The systematic increase in difficulty level was assured by systematically selecting every third item from a standardized word reading test (Three-Minute Reading test; Verhoeven, 1995) for which the gradual increase in difficulty level was demonstrated. The child was instructed to read the words as accurately as possible. There was no time limit. Testing was terminated if the child read six consecutive items incorrectly.

Nonword reading accuracy. This test was similar to the word reading accuracy test but it consisted of nonwords instead of real words. The test consisted of 40 items that gradually increased in difficulty level. The systematic increase in difficulty level was assured by selecting every third item from a standardized nonword identification test (Pseudoword Reading test, Version B; van den Bos, Spelberg, Scheepstra, \& de Vries, 1994) for which this gradual increase in difficulty level was demonstrated. The child was instructed to read the nonwords as accurately as possible. There was no time limit. Testing was terminated if the child read six consecutive items incorrectly.

Word reading speed. We used a reading test with items that were of equal difficulty level and that yielded nearly perfect accuracy (Peeters, 2005). The test consisted of 150 high-frequent one-syllable words with a consonant-vowel, vowel-consonant, or consonant-vowel-consonant structure. All words were known by more than $90 \%$ of the Dutch speaking 6-year-olds (Schaerlaekens, Kohnstamm, \& Lejaeghere, 1999). The child was instructed to read the list of words as correctly and quickly as possible. The number of words read within $1 \mathrm{~min}$ was transformed into the number of words read per second.

Nonword reading speed. This test was similar to the word reading speed test. It consisted of items that were of equal difficulty level and that yielded nearly perfect accuracy (Peeters, 2005). The test consisted of 150 one-syllable nonwords with a consonant-vowel, vowel-consonant, or consonant-vowel-consonant structure. These items were constructed by decomposing and recombining the items of the word reading speed test. The number of nonwords read within $2 \mathrm{~min}$ was transformed into the number of nonwords read per second.

Spelling. A standardized spelling achievement test (Dudal, 1997) was used to assess children's spelling abilities. Children had to spell single words presented in isolation, single words pre- sented in sentence context, and short sentences. The maximum score on the test was 60. For diagnostic purposes, this score was transformed to an ageadjusted standard score relative to population average. Grade-appropriate versions of the test were used in first and third grades.

\section{Detection Test}

For the $\mathrm{CM}$ detection test, children sat in a dimly lit room, $40 \mathrm{~cm}$ from the 17 -in. screen $(75 \mathrm{~Hz}$ vertical refresh rate) on which the RDK were displayed. The stimuli comprised two rectangular patches each of which contained 1,103 high-luminance, moving white dots on a black background (dot size $=1$ pixel or $0.07^{\circ}$ diameter, dot density $=2.5$ dots $/ \mathrm{deg}^{2}$, velocity $=7.3 \mathrm{deg} / \mathrm{s}$, life time $=5$ video frames or $200 \mathrm{~ms}$, maximal duration of stimulus presentation $=6 \mathrm{~s}$, luminance of dots $=125 \mathrm{~cd} / \mathrm{m}^{2}$, luminance of background $=0.39 \mathrm{~cd} / \mathrm{m}^{2}$, Michelson contrast $=99.4 \%$ ). Each patch of dots subtended $16 \times 27.2^{\circ}$ visual angle and was separated horizontally by $3.8^{\circ}$. The target patch was segregated into three horizontal strips (similar but not identical to Gunn et al., 2002). In the middle strip, a variable proportion of coherent dots were moving horizontally, reversing direction every $330 \mathrm{~ms}$ (cf. Atkinson et al., 2003). This created the impression of "a road emerging in the snow." All other dots underwent Brownian motion. Children had to identify the patch that contained the strip of coherently moving dots. Threshold was defined as the smallest proportion of coherently moving dots required for detection and was estimated using a two-down, one-up adaptive staircase procedure, which targeted the threshold corresponding to 70.7\% correct responses (Levitt, 1971). Thresholds for an individual run were calculated by the geometric mean of the values of the last four of eight reversals. After a short period of practice, four thresholds were determined for every subject. The experiment was integrated within a computer game with animation movies and an extensive reinforcement system to make it applicable for young children. A more detailed description of the procedure and equipment can be found in Boets et al. (2006b).

\section{Statistical Analysis}

To account for the clustered nature of the data (i.e., matched pairs attending the same school), a series of repeated measures MMAs was calculated with pair number (1-31) as a random variable, 
group (D, NHR, and NLR) as a between-subject variable, and threshold run (1-4) as a within-subjects variable (Littell, Stroup, \& Freund, 2002). Kenward-Roger's degrees of freedom estimation method was used, which is more robust against violations to assumptions of normality and more appropriate for small sample sizes (Kowalchuk, Keselman, Algina, \& Wolfinger, 2004). Post hoc analyses were corrected for multiple comparisons using the Tukey procedure $(\alpha=.05)$, and Cohen's $d$ effect sizes were calculated by dividing the difference between the least square means by the pooled standard deviation.

To explore the directionality of the observed correlations, a cross-lagged causal path analysis, adjusted for small sample size, was calculated on the data partialed out for individual differences in nonverbal intelligence. Analysis of the covariance matrices was conducted with LISREL 8.71 (Jöreskog \& Sorböm, 2004) and solutions were generated on the basis of maximum-likelihood estimation. Because of violations of normality, the asymptotic covariance matrix was used as input and the Satorra-Bentler Scaled chi-square test was inspected $\left(\mathrm{SBS} \chi^{2}\right)$. A small and insignificant score on this test is indicative of a good model fit (Kline, 1998). To account for the small sample size, Bartlett's $k$-factor correction (Bartlett, 1950) was applied (for a detailed methodological account of the robustness of this small sample approach, see Fouladi, 2000; Nevitt \& Hancock, 2004). To further evaluate model goodness of fit, the comparative fit index (CFI), the root mean square error of approximation (RMSEA), and the standardized root mean square residuals (SRMR) were selected. According to $\mathrm{Hu}$ and Bentler (1999), the combined cutoff values above 0.95 for CFI, below .08 for RMSEA, and below .09 for SRMR indicate good model fit. Nested models were compared by means of a chi-square difference test $\left(\Delta \mathrm{SBS} \chi^{2}\right)$. A high and significant score on this chi-square difference test indicates that the more elaborated model provides a significantly better fit to the data compared with the baseline model.

\section{Results}

\section{Reliability and Longitudinal Stability of CM Measures}

Test-retest reliability was moderate to high: The Spearman rank correlation between two subsequent runs ranged between .67 and .80 in kindergarten, and between .57 and .73 in first grade $(p<.0001)$. An analysis of the longitudinal stability from kin- dergarten to first grade indicated that individual differences in processing $\mathrm{CM}$ were relatively stable (total group: $r_{s}=.48, p<.0001$ ), particularly in the NLR group $\left(r_{s}=.66, p=.0003\right)$ and in the NHR group $\left(r_{s}=.58, p=.007\right)$. For the children in the dyslexic group, individual differences in CM sensitivity were less stable $\left(r_{s}=.36, p=.18\right)$.

\section{Group Comparisons}

The preschool CM data of 1 child in the NLR group were discarded because of irregularities during testing. To obtain normally distributed residuals, CM thresholds were log-transformed prior to analysis. Average CM thresholds for the three groups of children, estimated in kindergarten and first grade, are displayed in Figure 1. First, we compared the performance of the three groups over the four threshold runs assessed in kindergarten. A clustered repeated measures MMA with group as between-subject variable and threshold run as within-subject variable revealed a significant effect of group, $F(2,43.8)=4.22, p=.02 ;$ a significant effect of threshold run, $F(3,174)=18.48, p<.0001$; and no significant Group $\times$ Run interaction effect, $F(6,174)=1.23, p=.29$. Post hoc analysis indicated that children in the dyslexic group showed significantly higher thresholds than children in the NLR and NHR groups ( $d$ s were 0.85 and 0.97 , respectively), who themselves did not differ from each other $(d=0.10)$. Furthermore, for all groups there was a significant learning effect from the first to the second run $(d=0.55)$; the second, third, and fourth

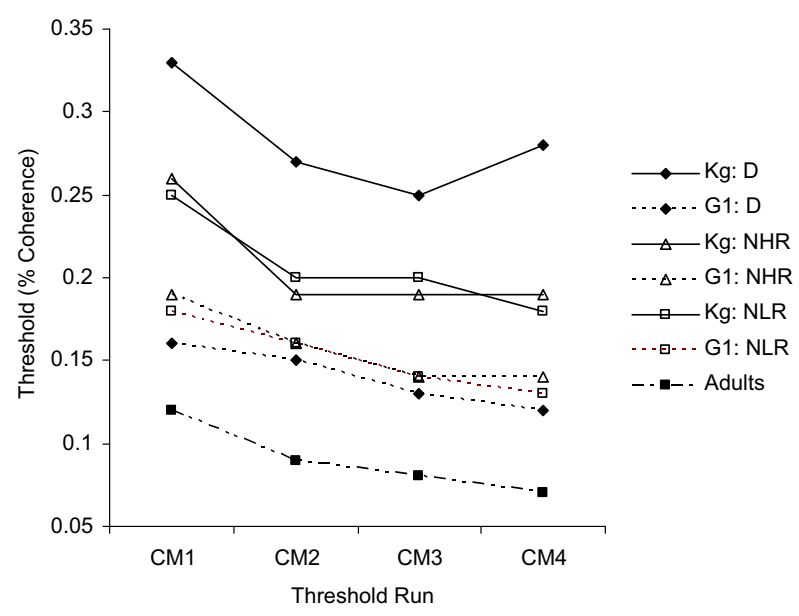

Figure 1. Average coherent motion thresholds for children of the dyslexic reading group (D), the nondyslexic high-risk group (NHR), and the nondyslexic low-risk group (NLR) in kindergarten $(\mathrm{Kg})$ and Grade $1(\mathrm{G} 1)$, and for the group of adults. Note. The average threshold for every run is presented. 
runs did not differ significantly from each other ( $d s$ ranging between -0.02 and 0.14 ). A reanalysis of the data with the average of the best and secondbest threshold as an alternative indicator of sensory sensitivity (see Boets et al., 2006b) yielded an identical group effect, $F(2,43.8)=4.57, p=.016$, with $d$ equaling $0.70,0.78$, and 0.09 for the D-NHR, D-NLR, and NHR-NLR contrasts, respectively.

Second, a clustered repeated measures MMA on the CM thresholds assessed in first grade yielded no significant effect of group, $F(2,45.4)=0.40$, $p=.87$; a significant effect of threshold run, $F(3$, $177)=19.97, p<.0001$; and no significant Group $\times$ Run interaction effect, $F(6,177)=0.28, p=.95$. Post hoc testing indicated that none of the four threshold measures differentiated between the groups ( $d s$ ranged between -0.19 and 0.10 ) and that all runs differed significantly from each other, apart from the third and the fourth runs. A reanalysis with the average of the best and second-best threshold yielded similar null results, $F(2,46.1)=0.12$, $p=.89$, with $d$ equaling $-0.17,-0.04$, and 0.10 for the D-NHR, D-NLR, and NHR-NLR contrasts, respectively.

To investigate the development of CM sensitivity from kindergarten to Grade 1, a clustered repeated measures MMA with group as between-subject variable and age (kindergarten vs. Grade 1) as withinsubject variable was carried out on the average of the best and second-best threshold (see Figure 2). This analysis revealed a significant effect of age, $F(1,57.7)=70.73, p<.0001$; no significant effect of

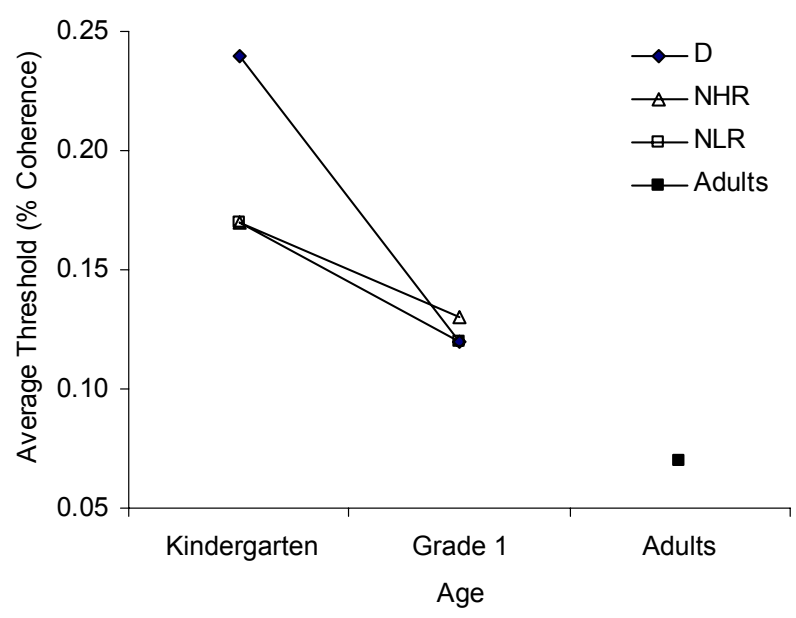

Figure 2. Development in coherent motion sensitivity: Average coherent motion thresholds for the dyslexic reading group (D), the nondyslexic high-risk group (NHR), and the nondyslexic low-risk group (NLR) in kindergarten and Grade 1, and for the group of adults. group, $F(2,45.4)=1.35, p=.27 ;$ and a significant Group $\times$ Age interaction effect, $F(2,57.8)=5.17$, $p=.008$. Post hoc analysis confirmed that the thresholds of the dyslexic group differed from both other groups in kindergarten but not in Grade 1, that the improvement in CM sensitivity from kindergarten to Grade 1 was significant for all groups (ds were $-2.00,-0.94$, and -0.87 for the D, NHR, and NLR group, respectively), and that this improvement was the most substantial for the dyslexic group.

To verify whether $\mathrm{CM}$ thresholds might have reached ceiling level in Grade 1, the test was also administered to a group of 12 nonreading disabled adults, aged between 24 and 28 years ( 8 women and 4 men). Their reading abilities were evaluated with the same standardized word reading test that we used to assess the children (van den Bos et al., 1994). Compared to a reference group of 18-yearolds, all adults scored above the 60th percentile on this word reading test.

Average CM thresholds for this group of adults are also displayed in Figures 1 and 2. An MMA (which also controlled for the clustered nature of the child data) revealed that adults obtained significantly lower CM thresholds than any of the child groups assessed in kindergarten or Grade 1, $F(6$, $101)=22.75, p<.0001$, Tukey corrected, $d$ s ranged between -3.33 and -1.90 .

\section{Relations Between Coherent Motion Sensitivity and Literacy Achievement}

The relation between average $\mathrm{CM}$ thresholds and measures of literacy achievement was further explored in the group of dyslexic readers and in the typically developing control group (NLR; see Table 2). As the six reading measures were highly correlated (correlations ranged from .71 to .95 , $p<.0001$ ), they were grouped into a single reading composite score by transforming the raw score on each reading test into a $z$ score and by averaging these $z$ scores. Since CM thresholds were significantly related to scores on Raven's Colored Progressive Matrices (correlations equaled -.32 in kindergarten and -.28 in first grade, $p<.05$ ), correlations were partialed out for individual differences in nonverbal intelligence. Spearman rank correlations were calculated to ensure that the relations were not determined by outlying subjects.

In the NLR group significant concurrent and predictive relations were observed between $\mathrm{CM}$ thresholds assessed in kindergarten and letter knowledge in kindergarten and first grade, reading 
Table 2

Spearman Partial Correlations Between Coherent Motion Thresholds Measured in Kindergarten and Grade 1, and Literacy Achievement Measured in Kindergarten, Grade 1, and Grade 3

\begin{tabular}{|c|c|c|c|c|}
\hline \multirow[b]{3}{*}{ Literacy measures } & \multicolumn{2}{|c|}{ Dyslexic group } & \multicolumn{2}{|c|}{$\begin{array}{c}\text { Nondyslexic } \\
\text { low-risk group }\end{array}$} \\
\hline & $\mathrm{CM}$ & $\mathrm{CM}$ & $\mathrm{CM}$ & $\mathrm{CM}$ \\
\hline & \multicolumn{4}{|c|}{ kindergarten Grade 1 kindergarten Grade } \\
\hline \multicolumn{5}{|l|}{ Kindergarten } \\
\hline Letter knowledge & -.16 & -.37 & $-.71^{* * *}$ & $-.52^{* *}$ \\
\hline \multicolumn{5}{|l|}{ Grade 1} \\
\hline Letter knowledge & -.27 & -.37 & $-.42^{*}$ & -.22 \\
\hline Reading composite & -.06 & $-.60^{* *}$ & $-.42^{*}$ & -.10 \\
\hline Spelling & -.01 & -.29 & -.20 & .13 \\
\hline \multicolumn{5}{|l|}{ Grade 3} \\
\hline Reading composite & -.16 & $-.53^{*}$ & $-.35^{\dagger}$ & -.06 \\
\hline Spelling & -.21 & -.27 & $-.41^{*}$ & -.14 \\
\hline
\end{tabular}

Note. All correlations are partialed out for individual differences in nonverbal intelligence (Raven's Colored Progressive Matrices). $\mathrm{CM}=$ coherent motion.

${ }^{\dagger} p<10 .{ }^{*} p<.05 .{ }^{* *} p<.01 .{ }^{* * *} p<.001$.

achievement in first grade, and spelling achievement in third grade. For the CM thresholds assessed in Grade 1, no significant relations with concurrent and future literacy achievement were observed in this group.

For children in the dyslexic group, no significant relations were observed between $\mathrm{CM}$ thresholds assessed in kindergarten and concurrent and future literacy achievement measures. One year later, however, a significant relation emerged between $\mathrm{CM}$ thresholds measured in first grade and reading achievement in first and third grades.

To verify whether $\mathrm{CM}$ sensitivity independently influenced growth in literacy achievement or whether its relation with later literacy measures was just a result of its relation with concurrently assessed literacy achievement, an additional set of partial correlations was calculated that also controlled for the autoregressive effect of kindergarten letter knowledge. The underlying logic was that if $\mathrm{CM}$ sensitivity contributes uniquely to individual differences in the growth of literacy skills, then it should also explain differences in literacy outcome independently of prior literacy status. The results of this additional analysis revealed two interesting findings. First, in the NLR group, CM thresholds assessed in kindergarten still predicted individual differences in first-grade letter knowledge $\left(r_{s}=-.50, p=.01\right)$, even after taking into account individual differences in prior letter knowledge and nonverbal intelligence. Second, in the dyslexic group, CM thresholds assessed in Grade 1 uniquely predicted individual differences in reading achievement $\left(r_{s}=-.57, p=.02\right)$ after controlling for prior letter knowledge and nonverbal intelligence.

Likewise, we verified whether the observed predictive relation between letter knowledge in kindergarten and CM sensitivity in first grade in the NLR group would assert while taking into account the autoregressive effect of preschool CM sensitivity. This correlation did not hold $\left(r_{s}=-.10, p=.64\right)$, which suggests that letter knowledge in kindergarten did not independently affect CM sensitivity in first grade.

To further explore the directionality of the aforementioned correlations between CM processing and letter knowledge, a cross-lagged causal path analysis, adjusted for small sample size, was calculated on the NLR data partialed out for individual differences in nonverbal intelligence. This model allows examination of the relation between one behavioral construct assessed in kindergarten and another construct assessed in Grade 1, while taking into account autoregressive effects and crosssectional covariances. If one of the time-lagged cross-paths is significantly stronger than the other, it suggests a directional effect (Finkel, 1995). Four structural models were tested and compared. First, an autoregressive model or baseline model (M1), which only included autoregressive effects and cross-sectional covariances, was fitted. The second model (M2) was a unidirectional model with a cross-effect of CM processing in kindergarten upon letter knowledge in Grade 1. The third model (M3) was a unidirectional model with a cross-effect of letter knowledge in kindergarten upon CM processing in Grade 1. Finally, the fully saturated model (M4) was fitted to compare the regression weights on the cross-paths.

The fully saturated model with standardized regression weights is depicted in Figure 3 and fit indices for the four models are displayed in Table 3. As can be seen in Table 3, the baseline model (M1) did not show an adequate fit to the data. Results showed that Model M2 (with addition of the cross-path from CM in kindergarten to letter knowledge in Grade 1) significantly improved upon the baseline model, $\Delta \mathrm{SBS} \chi^{2}(1)=4.50, p<.05$, and resulted in a satisfactory model fit. On the contrary, addition of the cross-path from letter knowledge in kindergarten to CM in Grade 1 (Model M3) did not produce a significantly better fit, $\Delta \mathrm{SBS} \chi^{2}(1)=1.32$, $p=.25$. In a similar way, examination of the crosspath regression weights of the fully saturated 


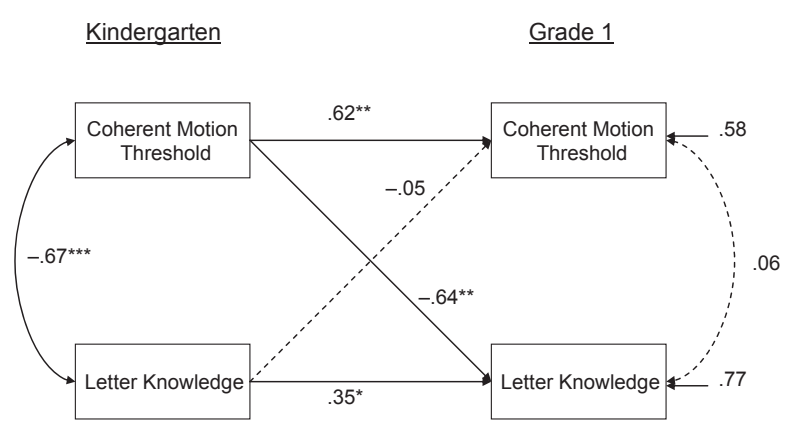

Figure 3. Cross-lagged causal path analysis modeling the relations between coherent motion processing and letter knowledge in kindergarten and Grade 1: Fully saturated model. ${ }^{*} p<.05 .{ }^{* *} p<.01 .{ }^{* * *} p<.001$.

Model M4 also supported the hypothesis of a unidirectional influence of $\mathrm{CM}$ processing upon letter knowledge: The fully saturated model revealed a significant path between $\mathrm{CM}$ thresholds in kindergarten and letter knowledge in Grade $1(\beta=-.64$, $p<.01)$, whereas the relation between letter knowledge in kindergarten and $\mathrm{CM}$ thresholds in Grade 1 was not significant $(\beta=-.05, p=.61)$.

\section{Are the Observed Deficits and Correlations a Corollary of ADHD-Related Behavior?}

Performance on psychophysical tasks is also determined by nonsensory factors, such as sustained attention. In this context, it has been suggested that dyslexics' sensory deficits could be an artifact of the generally increased incidence of attention-related disorders (ADHD or ADD) in the reading disabled population (Breier, Fletcher, Foorman, Klaas, \& Gray, 2003; Hulslander et al., 2004; Ramus, 2003). Given the challenges and complexities of psychophysical testing of preschool children, inclusion of subjects with attention problems might be particularly detrimental for the $\mathrm{CM}$ thresholds obtained in kindergarten. Correlation of the ADHD rating scale with $\mathrm{CM}$ thresholds, however, demon- strated that CM thresholds were not related to any indicator of ADHD-related problem behavior (Spearman correlations ranged from -.10 to .17, $p>$.20). To further rule out the possible influence of individual differences in attention, hyperactivity or impulsivity, scores on the ADHD rating scale(s) were entered into the group comparisons as a covariate and were partialed out from the correlations. This reanalysis revealed identical results as those described earlier: Actually every significant effect was retained or became even more pronounced, for the group comparisons as well as for the correlations. Taken together, these findings suggest that the reduced CM sensitivity in preschool children that ultimately develop dyslexia and the relation between preschool CM thresholds and future literacy achievement are not a consequence of comorbid attention problems.

\section{Discussion}

There exists considerable evidence that $\mathrm{CM}$ sensitivity is impaired in individuals with dyslexia and that $\mathrm{CM}$ detection thresholds are correlated with various aspects of literacy achievement in the general population. However, the nature of this association remains largely unknown. This study applied a longitudinal design to investigate whether $\mathrm{CM}$ sensitivity assessed in kindergarten before the start of formal reading instruction may be predictive for the development of literacy abilities and disabilities in first and third grades.

Children who ultimately were diagnosed as having dyslexia in third grade showed significantly impaired CM sensitivity in kindergarten compared with carefully matched nondyslexic readers. This reduction in motion sensitivity was identified before these children had been exposed to formal reading and spelling instruction in school. This finding suggests that whatever is the reason for

Table 3

Goodness-of-Fit Indices for the Four Structural Models

\begin{tabular}{lcrr}
\hline Model & SBS $\chi^{2}$ (with $k$-factor correction) & CFI & RMSEA \\
\hline M1: Baseline model & $\mathrm{SBS} \chi^{2}(2)=4.57, p=.08$ & .88 & .26 \\
M2: CM kindergarten to LK Grade 1 & $\mathrm{SBS} \chi^{2}(1)=0.07, p>.25$ & 1.00 & .00 \\
M3: LK kindergarten to CM Grade 1 & $\mathrm{SBS} \chi^{2}(1)=3.25, p=.07$ & .90 & .01 \\
M4: Complete model & $\mathrm{SBS} \chi^{2}(0)=0.00, p=1.00$ & 1.00 & .33 \\
\hline
\end{tabular}

Note. $\mathrm{CM}=$ coherent motion processing; $\mathrm{LK}=$ letter knowledge; $\mathrm{SBS} \chi^{2}=$ Satorra-Bentler scaled chi-square test; $\mathrm{CFI}=$ comparative fit index; RMSEA = root mean square error of approximation; SRMR = standardized root mean square residuals. 
impaired performance on a motion detection task, the problem precedes later literacy difficulties. Moreover, it refutes the idea that reduced CM sensitivity arises as a consequence of impaired reading ability and reduced print exposure.

We also found that $\mathrm{CM}$ sensitivity measured in kindergarten was a significant predictor of literacy development in typically developing, nonreading disabled children, even when general cognitive abilities, co-occurring attention problems, and the autoregressive effect of prior literacy skills were statistically controlled for. We used path analysis to test the directionality of this association and confirmed that CM sensitivity in kindergarten significantly predicted letter knowledge in first grade, but letter knowledge in kindergarten did not predict $\mathrm{CM}$ sensitivity in first grade (see Figure 3 ).

Although we acknowledge that causal inference requires an intervention study or a true experimental design, the present longitudinal data strongly suggest that better $\mathrm{CM}$ sensitivity promotes greater reading proficiency during development. If we assume that CM detection thresholds index dorsal visual stream integrity (see Britten et al., 1992; Newsome \& Pare, 1988), it is plausible that the degree of dorsal stream integrity sets constraints on literacy acquisition. The exact mechanism by which visual dorsal stream integrity affects literacy development cannot be inferred by our study. Together with Boden and Giaschi (2007), we would contend that visual attention, letter position encoding, binocular stability, and oculomotor control may play an important intermediate role in it, particularly because all these visual dorsal stream processes have been shown to be impaired in individuals with dyslexia.

Once they had reached first grade, the participants in this study repeated the same CM detection task that they had carried out in kindergarten. Now, 1 year later, while CM sensitivity had significantly improved for all three groups of children, we were no longer able to identify significant differences between them. Dyslexics' preschool CM sensitivity impairment had disappeared completely. In a similar vein, no concurrent and predictive relations between $\mathrm{CM}$ sensitivity measured in first grade, and reading and spelling ability in first and third grades in the typically developing control children could be observed. However, we did find significant concurrent and predictive relations between firstgrade $\mathrm{CM}$ sensitivity and first- and third-grade reading ability in the children with dyslexia (even after taking into account general cognitive ability,
ADHD ratings and the autoregressive effect of previous letter knowledge).

How can we interpret this pattern of results? How can we understand the drastic shift in CM sensitivity in the children with dyslexia? Intuitively, it seems difficult to reconcile this finding with the observation that CM thresholds show good testretest reliability and stability over time, at least in the nondyslexic children. In what follows, we propose a number of tentative explanations, but further research is needed to offer a more comprehensive account of this challenging finding.

One possibility is that the CM task was too easy for first-grade children, so they all performed at ceiling. However, comparing CM detection thresholds of children with those of adults showed that there was plenty of opportunity for children's sensitivity to improve further; only 2 children produced adult-level performance. In addition, there was clearly enough individual variation in $\mathrm{CM}$ detection thresholds obtained in first grade for us to observe correlations with the other outcome variables.

A related possibility is that first-grade children, although not performing at adult level, nevertheless achieved an age-appropriate ceiling for $\mathrm{CM}$ task performance. This also implies that dyslexic children, despite being delayed in acquiring their ageappropriate motion sensitivity when observed in kindergarten, nevertheless achieved it by first grade. There are a number of aspects of our CM stimulus and study design that make this a viable explanation. First, our study is unique in administering eight threshold runs split between two test points, and it may therefore have offered maximal "learning" opportunities for the CM task. Second, we used a relatively easy version of the CM task, whose parameters were originally designed for use in children with mental retardation (Atkinson et al., 1997) and hemiplegic cerebral palsy (Gunn et al., 2002). Specifically, the target patch was segregated into three strips with opposite moving middle strip, which makes it easier to identify. Third, the stimulus display subtended an unusually large visual angle compared to other studies. As a result, the CM stimulus was largely presented in the parafoveal regions, which are more sensitive to stimulus motion (Merigan \& Maunsell, 1993). This may have facilitated detection of the target patch. Fourth, a high total number of dots was used (i.e., 1,103) to accommodate this large stimulus field with a dot density that was equivalent to other dyslexia studies. Dot density was taken into account because it has been shown that increased dot density may 
relieve dyslexics' $\mathrm{CM}$ detection impairment by accumulating the total amount of motion energy in a particular direction (Talcott, Hansen, et al., 2000). Along these lines, it is not implausible that the increased total dot number may also have improved the CM sensitivity of the dyslexic children in our study by boosting the effective signal to noise ratio. It is plausible that because of the combination of these specific task characteristics, the $\mathrm{CM}$ task we used in this study was only capable of differentiating between the performance levels of preschool children, whereas a more typical CM paradigm might also be expected to distinguish dyslexic from nondyslexic performance at first grade, third grade, and in adults. However, a systematic investigation of the parameters of the CM tasks used in 26 previous dyslexia studies does not seem to support this hypothesis. Three studies in which four or more consecutive threshold runs were administered (Conlon et al., 2004; Cornelissen et al., 1995; Raymond \& Sorensen, 1998) showed significant group differences between dyslexic and nondyslexic individuals. One study in which a CM task was administered where the target patch was segregated into three strips like this study (Cornelissen et al., 1995) showed significant group differences. Two of the three dyslexia studies that investigated $\mathrm{CM}$ sensitivity with a stimulus display containing more than 300 dots observed significant group differences (i.e., Cornelissen et al., 1995; Slaghuis \& Ryan, 1999). Moreover, the third study, which did not observe group differences with a stimulus display with 600 dots (Talcott, Hansen et al., 2000), attributed this finding to the increased dot density and not to the increased total number of dots. Finally, the task parameters of the six dyslexia studies that showed no differences between dyslexics' and nondyslexics' motion thresholds (Amitay et al., 2002; Hutzler et al., 2006; Kim \& Davis, 2004; Kronbichler et al., 2002; Tsermentseli et al., 2008; White et al., 2006), were no different from those studies in which group differences were observed.

The general pattern of results that we found for $\mathrm{CM}$ sensitivity in this study may, to some extent, mirror the developmental trajectory of phonological awareness skills and their predictive relation with reading and spelling (e.g., de Jong \& van der Leij, 2003; Elbro \& Scarborough, 2003). Typically, at preschool, rhyme awareness tasks reliably differentiate between children who will become good versus poor readers. They are good predictors of future literacy skills, particularly for children scoring at or above average (Bradley \& Bryant, 1985). In first grade, however, most children master these rhyming skills and achieve ceiling performance in the tasks (partly as a consequence of learning to read). Consequently, the predictive and differentiating power of the rhyming tasks drops considerably. About this time, more advanced and fine-grained phonological skills like phoneme awareness come into play, and these now start to determine literacy development. Yet, although the poorly reading subjects considerably improved their rhyming skills, these rhyme awareness tasks may still show enough residual variability in first grade to predict within-group variation in literacy development in the dyslexic reading group.

A similar developmental pattern may be apparent in this study with regard to $\mathrm{CM}$ sensitivity. Assuming that the analogy with phonological skill development is legitimate, a key issue concerns the question why these poor performers suddenly improved CM sensitivity between kindergarten and first grade. A major difference between the two measurement points is that children had received formal reading and writing instruction in between times. With respect to phonological processing, it has been shown that letter knowledge and learning to read significantly boost phonological awareness (e.g., Morais, Cary, Bertelson, \& Alegria, 1979), hence substantiating the evidence of a bidirectional relation between phonological awareness and learning to read (Bentin \& Leshem, 1993). With respect to $\mathrm{CM}$ sensitivity, it has also been suggested that improved sensory sensitivity could be a consequence and not a cause of improving literacy skills (Ramus, 2003; Talcott \& Witton, 2002). Learning to read requires a child to adequately program eye movements and focus attention to decipher and spatially encode a series of small visual symbols (Morrison, 1984). It seems that learning to read targets a number of task-relevant dorsal stream processes, such as selective visual attention, spatial position encoding, and oculomotor control (see Boden \& Giaschi, 2007). Not all visual functions are fully mature in children when they enter primary school (e.g., eye movement control; Hainline, 1988). Although the neural framework is present from birth, visual input is necessary for synaptic connections to be further sculpted. Learning to read may therefore mean that dorsal visual stream functions are strongly mobilized and fine-tuned, with the result that the function of many of its network components becomes enhanced, and this could include motion processing in V5. Evidence that CM sensitivity can improve through training and that improvement in one dorsal stream skill may 
transfer to other untrained skills has been provided by Seitz, Nanez, Holloway, and Watanabe (2006). Thus, from a theoretical point of view it seems plausible that learning to read may interact with the maturation of visual dorsal stream processes. This may explain why all children, after receiving 9 months of reading instruction, obtained similar thresholds on an easy CM detection task. However, individual differences in letter knowledge in kindergarten did not independently predict individual differences in $\mathrm{CM}$ processing in first grade (although it was correlated).

To conclude, these longitudinal data corroborate the evidence for a relation between CM sensitivity and reading development. Preschool impairments in CM sensitivity, as a putative index of reduced visual dorsal stream integrity, are indicative for the emergence of reading and spelling problems in first and third grades. Individual differences in preschool CM sensitivity in typically developing children are also uniquely predictive for individual differences in first- and third-grade literacy achievement. Conversely, learning to read seems to mobilize and affect visual dorsal stream processing in such a way that the preschool group difference in $\mathrm{CM}$ sensitivity between dyslexic and nondyslexic readers equalizes after 9 months of reading practice. Future studies should apply interventional and experimental designs to investigate whether these longitudinal and directional effects and relations should be interpreted in a strict causal way.

\section{References}

Amitay, S., Ben-Yehudah, G., Banai, K., \& Ahissar, M. (2002). Disabled readers suffer from visual and auditory impairments but not from a specific magnocellular deficit. Brain, 125, 2272-2284.

Atkinson, J., Braddick, O., Anker, S., Curran, W., Andrew, R., Wattam-Bell, J., et al. (2003). Neurobiological models of visuospatial cognition in children with Williams syndrome: Measures of dorsal-stream and frontal function. Developmental Neuropsychology, 23, 139-172.

Atkinson, J., King, J., Braddick, O., Nokes, L., Anker, S., \& Braddick, F. (1997). A specific deficit of dorsal stream function in Williams' syndrome. Neuroreport, 8, 19191922.

Bartlett, M. S. (1950). Tests of significance in factor analysis. British Journal of Psychology, Statistical Section, 3, 7785.

Bentin, S., \& Leshem, H. (1993). On the interaction of phonological awareness and reading acquisistion: It's a two way street. Annals of Dyslexia, 43, 125-148.
Boden, C., \& Giaschi, D. (2007). M-stream deficits and reading-related visual processes in developmental dyslexia. Psychological Bulletin, 133, 346-366.

Boets, B., Wouters, J., van Wieringen, A., \& Ghesquiere, P. (2006a). Auditory temporal information processing in preschool children at family risk for dyslexia: Relations with phonological abilities and developing literacy skills. Brain and Language, 97, 64-79.

Boets, B., Wouters, J., van Wieringen, A., \& Ghesquiere, P. (2006b). Coherent motion detection in preschoolers at family risk for dyslexia. Vision Research, 46, 527-535.

Bradley, L., \& Bryant, P. (1985). Rhyme and reason in reading and spelling. Ann Arbor: University of Michigan Press.

Breier, J. I., Fletcher, J. M., Foorman, B. R., Klaas, P., \& Gray, L. C. (2003). Auditory temporal processing in children with specific reading disability with and without attention deficit hyperactivity disorder. Journal of Speech, Language and Hearing Research, 46, 31-42.

Britten, K. H., Shalden, M. N., Newsome, W. T., \& Movshon, J. A. (1992). The analysis of visual motion: A comparison of neuronal and psychophysical performance. Journal of Neuroscience, 12, 4745-4765.

Conlon, E., Sanders, M., \& Zapart, S. (2004). Temporal processing in poor adult readers. Neuropsychologia, 42, 142-157.

Cornelissen, P. L., Hansen, P. C., Gilchrist, I., Cormack, F., Essex, J., \& Frankish, C. (1998). Coherent motion detection and letter position encoding. Vision Research, 38, 2181-2191.

Cornelissen, P. L., Hansen, P. C., Hutton, J. L., Evangelinou, V., \& Stein, J. F. (1998). Magnocellular visual function and children's single word reading. Vision Research, 38, 471-482.

Cornelissen, P., Richardson, A., Mason, A., Fowler, S., \& Stein, J. (1995). Contrast sensitivity and coherent motion detection measures at photopic luminance levels in dyslexics and controls. Vision Research, 35, 1483-1494.

de Jong, P. F., \& van der Leij, A. (2003). Developmental changes in the manifestation of a phonological deficit in dyslexic children learning to read a regular orthography. Journal of Educational Psychology, 95, 22-40.

de Jong, P. F., \& Wolters, G. (2002). Fonemisch bewustzijn, benoemsnelheid en leren lezen [Phoneme awareness, rapid naming and reading acquisition]. Pedagogische Studieën, 79, 53-63.

Demb, J., Boynton, G., \& Heeger, G. (1997). Brain activity in visual cortex predicts individual differences in reading performance. Proceedings of the National Academy of Sciences, USA, 94, 13363-13366.

Dudal, P. (1997). Leerlingvolgsysteem VCLB (CSBO). Spelling: Toetsen 1-2-3. Basisboek en kopieerbundel [Student trajectory system. Spelling: Grade 1-2-3. Manual]. Leuven, Belgium: Garant.

Eden, G., Van Meter, J., Rumsey, J., Maisog, J., Woods, R., \& Zeffiro, T. (1996). Abnormal processing of visual motion in dyslexia revealed by functional brain imaging. Nature, 382, 66-69. 
Edwards, V., Giaschi, E., Dougherty, R. F., Edgell, D., Bjornson, B. H., Lyons, C., et al. (2004). Psychophysical indexes of temporal processing abnormalities in children with developmental dyslexia. Developmental Neuropsychology, 25, 321-354.

Elbro, C., \& Scarborough, H. S. (2003). Early identification. In P. Bryant \& T. Nunes (Eds.), Handbook of children's reading (pp. 339-359). Dordrecht, Netherlands: Kluwer.

Everatt, J., Bradshaw, M., \& Hibbard, P. (1999). Visual processing and dyslexia. Perception, 28, 243-254.

Finkel, S. E. (1995). Causal analysis with panel data. Thousand Oaks, CA: Sage.

Fouladi, R. T. (2000). Performance of modified test statistics in covariance and correlation structure analysis under condition of multivariate nonnormality. Structural Equation Modeling, 7, 356-410.

Gersons-Wolfensberger, D. C. M., \& Ruijssenaars, W. A. J. J. M. (1997). Definition and treatment of dyslexia: A report by the Committee on Dyslexia of the Health Council of the Netherlands. Journal of Learning Disabilities, 30, 209-213.

Gibson, L. Y., Hogben, J. H., \& Fletcher, J. (2006). Visual and auditory processing and component reading skills in developmental dyslexia. Cognitive Neuropsychology, 23, 621-642.

Gilger, J. W., Pennington, B. F., \& DeFries, J. C. (1991). Risk for reading disability as a function of parental history in three family studies. Reading and Writing, 3, 205-217.

Goodale, M. A., \& Milner, D. A. (1992). Separate visual pathways for perception and action. Trends in Neuroscience, 15, 20-25.

Gunn, A., Cory, E., Atkinson, J., Braddick, O., WattamBel, J., Guzzetta, A., et al. (2002). Dorsal and ventral stream sensitivity in normal development and hemiplegia. Neuroreport, 13, 843-847.

Hainline, L. (1988). Normal lifespan developmental changes in saccadic and pursuit eye movements. In C. W. Johnston \& F. J. Pirozzolo (Eds.), Neuropsychology of eye movements (pp. 31-64). Hillsdale, NJ: Erlbaum.

Hansen, P. C, Stein, J. F, Orde, S. R, Winter, J. L, \& Talcott, J. B. (2001). Are dyslexics' visual deficits limited to measures of dorsal stream function? Neuroreport, 12, 1527-1530.

Hendry, S. H. C., \& Reid, R. C. (2000). The koniocellular pathway in primate vision. Annual Review of Neuroscience, 23, 127-153.

Hu, L., \& Bentler, P. M. (1999). Cutoff criteria for fit indexes in covariance structure analysis: Conventional criteria versus new alternatives. Structural Equation Modeling, 6, 1-55.

Hulslander, J., Talcott, J., Witton, C., DeFries, J., Pennington, B., Wadsworth, S., et al. (2004). Sensory processing, reading, IQ and attention. Journal of Experimental Child Psychology, 88, 274-295.

Hutzler, F., Kronbichler, M., Jacobs, A. M., \& Wimmer, H. (2006). Perhaps correlational but not causal: No effect of dyslexic readers' magnocellular system on their eye movements during reading. Neuropsychologia, $44,637-648$.

Jöreskog, K. G., \& Sorböm, D. (2004). LISREL 8.71. Chicago: Scientific Software.

Kim, J., \& Davis, C. (2004). Characteristics of poor readers of Korean Hangul: Auditory, visual and phonological processing. Reading and Writing, 17, 153-185.

Kim, J., Davis, C., Burnham, D., \& Luksaneeyanawin, S. (2004). The effect of script on poor readers' sensitivity to dynamic visual stimuli. Brain and Language, 91, 326335.

Kline, R. B. (1998). Principles and practice of structural equation modeling. New York: Guilford.

Kowalchuk, R. K., Keselman, H. J., Algina, J., \& Wolfinger, R. D. (2004). The analysis of repeated measurements with mixed-model adjusted $\mathrm{F}$ tests. Educational and Psychological Measurement, 64, 224-242.

Kronbichler, M., Hutzler, F., \& Wimmer, H. (2002). Dyslexia: Verbal impairments in the absence of magnocellular impairments. Neuroreport, 13, 617-620.

Levitt, H. (1971). Transformed up-down methods in psychoacoustics. Journal of the Acoustical Society of America, 49, 467-477.

Littell, R. C., Stroup, W. W., \& Freund, R. J. (2002). SAS for linear models. Cary, NC: SAS Institute.

Livingstone, M. S., \& Hubel, D. H. (1988). Segregation of form, color, movement, and depth. Science, 240, 740749.

Lovegrove, B. (1996). Dyslexia and a transient/magnocellular pathway deficit: The current situation and future directions. Australian Journal of Psychology, 48(3), 167-171.

Martin, K. A. C. (1992). Parallel pathways converge. Current Biology, 2, 555-557.

Merigan, W. H., \& Maunsell, J. H. R. (1993). How parallel are the primate visual pathways? Annual Review of Neuroscience, 16, 369-402.

Milne, E., Swettenham, J., Hansen, P., Campbell, R., Jeffries, H., \& Plaisted, K. (2002). High motion coherence thresholds in children with autism. Journal of Child Psychology and Psychiatry, 43, 255-263.

Mishkin, M., Ungerleider, L. G., \& Macko, K. A. (1983). Object vison and spatial vision: Two cortical pathways. Trends in Neurosciences, 6, 414-417.

Morais, J., Cary, L., Bertelson, P., \& Alegria, J. (1979). Does awareness of speech as a sequence of phones arise spontaneously? Cognition, 7, 323-331.

Morrison, R. E. (1984). Manipulation of stimulus onset delay in reading: Evidence for parallel programming of saccades. Journal of Experimental Psychology: Human Perception and Performance, 10, 667-682.

Nandakumar, K., \& Leat, S.J. (2008). Dyslexia: A review of two theories. Clinical and Experimental Optometry, 91, 333-340.

Nassi, J. J., \& Callaway, E. M. (2009). Parallel processing strategies of the primate visual system. Nature Reviews Neuroscience, 10, 360-372. 
Nassi, J. J., Lyon, D. C., \& Callaway, E. M. (2006). The parvocellular LGN provides a robust disynaptic input to the visual motion area MT. Neuron, 50, 319-327.

Nevitt, J., \& Hancock, G. R. (2004). Evaluating small sample approaches for model test statistics in structural equation modeling. Multivariate Behavioral Research, 39, 439-478.

Newsome, W. T., \& Pare, E. B. (1988). A selective impairment of motion perception following lesions of the middle temporal visual area (MT). The Journal of Neuroscience, 8, 2201-2211.

Organisation for Economic Co-operation and Development. (1999). Classifying educational programmes: Manual for ISCED-97 implementation in OECD countries. Paris: Author.

Pavlidis, G. T. (1981). Do eye movements hold the key to dyslexia? Neuropsychologia, 19, 57-64.

Peeters, A. (2005). Fonologie in de lagere school. Het meten van fonologische vaardigheden met de 'Fonologische Test Batterij' en de band met verschillende aspecten van de leesen spellingvaardigheid bij kinderen van het eerste leerjaar. [Phonology in primary school. Measuring phonological skills and its relation with specific aspects of reading and spelling abilities in first grade.] Unpublished master's thesis, Faculty of Psychology and Educational Sciences, Katholieke Universiteit Leuven, Leuven, Belgium.

Pellicano, E., \& Gibson, L. Y. (2008). Investigating the functional integrity of the dorsal visual pathway in autism and dyslexia. Neuropsychologia, 46, 2593-2596.

Pennington, B. F. (2006). From single to multiple deficit models of developmental disorders. Cognition, 101, 385-413.

Ramus, F. (2003). Developmental dyslexia: Specific phonological deficit or general sensorimotor dysfunction? Current Opinions in Neurobiology, 13, 212-218.

Raven, J. C., Court, J. H., \& Raven, J. (1984). Manual for Raven's Progressive Matrices and Vocabulary Scales. London: Lewis.

Raymond, J., \& Sorensen, R. (1998). Visual motion perception in children with dyslexia: Normal detection but abnormal integration. Visual Cognition, 5, 389-404.

Ridder, W. H., Borsting, E., \& Banton, T. (2001). All developmental dyslexic subtypes display an elevated motion coherence threshold. Optometry and Vision Science, 78, 510-517.

Roach, N. W., \& Hogben, J. H. (2004). Attentional modulation of visual processing in adult dyslexia: A spatialcuing deficit. Psychological Science, 15(10), 650-654.

Samar, V. J., \& Parasnis, I. (2005). Dorsal stream deficits suggest hidden dyslexia among deaf poor readers: Correlated evidence from reduced perceptual speed and elevated coherent motion detection thresholds. Brain and Cognition, 58, 300-311.

Schaerlaekens, A. M., Kohnstamm, D., \& Lejaeghere, M. (1999). Streeflijst woordenschat voor zesjarigen (derde herziene druk) [Vocabulary achievement in six-year-olds (3rd ed.)]. Lisse, Netherlands: Swets \& Zeitlinger.
Scholte, E. M., \& van der Ploeg, J. D. (1998). ADHD Vragenlijst $(A V L)$. Handleiding [ADHD rating scale. Manual]. Lisse, Netherlands: Swets \& Zeitlinger.

Seitz, A. R., Nanez, J. E., Holloway, S. R., \& Watanabe, T. (2006). Perceptual learning of motion leads to faster flicker perception. PLoS ONE, 1(1), e28.

Skottun, B. C. (2000). The magnocellular deficit theory of dyslexia: The evidence from contrast sensitivity. Vision Research, 40, 111-127.

Skottun, B. C., \& Skoyles, J. R. (2006). Is coherent motion an appropriate test for magnocellular sensitivity? Brain and Cognition, 61, 172-180.

Skottun, B. C., \& Skoyles, J. R. (2008). Coherent motion, magnocellular sensitivity and the causation of dyslexia. International Journal of Neuroscience, 118, 185-190.

Slaghuis, W. L., \& Ryan, J. F. (1999). Spatio-temporal contrast sensitivity, coherent motion, and visible persistence in developmental dyslexia. Vision Research, 39, 651-668.

Snowling, M. J. (2000). Dyslexia (2nd ed.). Malden, MA: Blackwell.

Solan, H. A., Shelley-Tremblay, J. F., Hansen, P. C., \& Larson, S. (2007). Is there a common linkage among reading comprehension, visual attention, and magnocellular processing? Journal of Learning Disabilities, 40, 270-278.

Sperling, A. J., Lu, Z., Manis, F. R., \& Seidenberg, M. S. (2006). Motion perception deficits and reading impairment: It's the noise, not the motion. Psychological Science, 17, 1047-1053.

Stein, J. (2001). The magnocellular theory of developmental dyslexia. Dyslexia, 7, 12-36.

Stein, J. (2003). Visual motion sensitivity and reading. Neuropsychologia, 41, 1785-1793.

Stein, J., \& Fowler, M. S. (1993). Unstable binocular control in dyslexic children. Journal of Research in Reading, $16,30-45$.

Stein, J., \& Talcott, J. (1999). Impaired neuronal timing in developmental dyslexia. The magnocellular hypothesis. Dyslexia, 5, 59-77.

Stein, J., \& Walsh, V. (1997). To see but not to read; the magnocellular theory of dyslexia. Trends in Neuroscience, 20(4), 147-152.

Talcott, J. B., Gram, A., Van Ingelghem, M., Witton, C., Stein, J. F., \& Toennessen, F. E. (2003). Impaired sensitivity to dynamic stimuli in poor readers of a regular orthography. Brain and Language, 87, 259-266.

Talcott, J. B., Hansen, P. C, Assoku, E. L, \& Stein, J. F. (2000). Visual motion sensitivity in dyslexia: Evidence for temporal and energy integration deficits. Neuropsychologia, 38, 935-943.

Talcott, J. B., Hansen, P., Willis-Owen, C., McKinnell, I., Richardson, A., \& Stein, J. (1998). Visual magnocellular impairment in adult developmental dyslexics. NeuroOphtalmology, 20, 187-201.

Talcott, J. B., \& Witton, C. (2002). A sensory linguistic approach to the development of normal and impaired reading skills. In E. Witruk, A. Friederici, \& T. Lachmann 
(Eds.), Neuropsychology and cognition series. Basic functions of language and language disorders (pp. 213-240). Dordrecht, Netherlands: Kluwer.

Talcott, J. B., Witton, C., McLean, M. F, Hansen, P. C, Rees, A., Green, G. G., et al. (2000). Dynamic sensory sensitivity and children's word decoding skills. Proceedings of the National Academy of Science, USA, 97, 2952-2957.

Tsermentseli, S. T., O’Brien, J. M., \& Spencer, J. V. (2008). Comparison of form and motion coherence processing in autistic spectrum disorders and dyslexia. Journal of Autism and Developmental Disorders, 38, 1201-1210.

van den Bos, K. P., Spelberg, H. C. L., Scheepstra, A. J. M., \& De Vries, J. R. (1994). De Klepel. Vorm A en B. Een test voor de leesvaardigheid van pseudowoorden. Verantwoording, handleiding, diagnostiek en behandeling [Word and Nonword Reading Test, A \& B. Manual]. Nijmegen, Netherlands: Berkhout.

Vellutino, F. R., Fletcher, J. M., Snowling, M. J., \& Scanlon, D. M. (2004). Specific reading disability (dyslexia): What have we learned in the past four decades? Journal of Child Psychology and Psychiatry, 45, 2-40.

Verhoeven, L. (1995). Drie-Minuten-Toets. Verantwoording [Three-Minute Reading Test. Manual]. Arnhem, Netherlands: Cito.

Vidyasagar, T. R. (2004). Neural underpinnings of dyslexia as a disorder of visuo-spatial attention. Clinical Experimental Optometry, 87, 4-10.
Walker, K. M., Hall, S. E., Klein, R. M., \& Phillips, D. P. (2006). Development of perceptual correlates of reading performance. Brain Research, 1124, 126-141.

Wechsler, D. (1992). Wechsler Intelligence Scale for Children (3rd ed. NL). London: Psychological Corporation.

White, S., Milne, E., Rosen, S., Hansen, P., Swettenham, J., Frith, U., et al. (2006). The role of sensorimotor impairments in dyslexia: A multiple case study of dyslexic children. Developmental Science, 9, 237-255.

Willcutt, E. G., \& Pennington, B. F. (2000). Comorbidity of reading disability and attention deficit/hyperactivity disorder: Differences by gender and subtype. Journal of Learning Disabilities, 33, 179-191.

Wilmer, J. B., Richardson, A. J., Chen, Y., \& Stein, J. F. (2004). Two visual motion processing deficits in developmental dyslexia associated with different reading skills deficits. Journal of Cognitive Neuroscience, 16, 528540 .

Witton, C., Talcott, J. B, Hansen, P. C, Richardson, A. J, Griffiths, T. D, \& Rees, et al. (1998). Sensitivity to dynamic auditory and visual stimuli predicts nonword reading ability in both dyslexic and normal readers. Current Biology, 8(14), 791-797.

Zeki, S. M. (1978). Functional specialization in the visual cortex of the rhesus monkey. Nature, 274, 423-428. 